\title{
The role of sentinel lymph node biopsy for melanoma: Evidence assessment
}

\author{
Timothy M. Johnson, MD, ${ }^{\mathrm{a}, \mathrm{b}, \mathrm{c}}$ Vernon K. Sondak, MD, ${ }^{\mathrm{d}}$ Christopher K. Bichakjian, MD, ${ }^{\mathrm{a}}$ \\ and Michael S. Sabel, $\mathrm{MD}^{\mathrm{c}}$ \\ Ann Arbor, Michigan, and Tampa, Florida
}

$\mathrm{T}$ hree decades after the first clinical trial of elective lymph node dissection (ELND) was initiated, the value and acceptance of sentinel lymph node (SLN) biopsy (SLNB) for patients with clinically localized melanoma remains a controversial issue with broad disparity in practice within the specialty of dermatology. ${ }^{1-5}$ On opposing sides of the argument are real and theoretic benefits of SLNB that have been advocated juxtaposed against reasonable and justifiable concerns that have been raised by critics. Many questions remain unanswered and future trial results may or may not support reasons for performing SLNB today. The commonly cited sometimes heated current debate is interesting in itself, considering the fact that the majority of patients with melanoma are given a diagnosis of thin primary tumors or already have clinically evident metastases and, hence, do not fall within the current guidelines for consideration of SLNB. ${ }^{1,6}$

New evidence often invalidates previously accepted therapy and replaces it with better and safer treatments. The optimal practice of medicine requires the fluid integration of clinical expertise with the best available levels of evidence and the patient's personal preferences and circumstances. Unfortunately in the evidence-based era, highestlevel evidence is still lacking for the majority of disease states. Physicians need to be aware of the current best available evidence, how to judge levels

\footnotetext{
From the Departments of Dermatology, ${ }^{a}$ Otolaryngology, ${ }^{b}$ and Surgery, ${ }^{c}$ University of Michigan Medical School; and Division of Cutaneous Oncology, Department of Interdisciplinary Oncology, H. Lee Moffitt Cancer Center and Research Institute, University of South Florida College of Medicine. ${ }^{d}$

Funding sources: None.

Conflicts of interest: None identified.

Reprint requests: Timothy M. Johnson, MD, University of Michigan Health System, 1910 Taubman Center, 1500 E Medical Center Dr, Ann Arbor, Ml 48109-0314. E-mail: timjohn@med.umich.edu. J Am Acad Dermatol 2006;54:19-27.

Published online December 5, 2005.

0190-9622/\$32.00

(c) 2005 by the American Academy of Dermatology, Inc.

doi:10.1016/j.jaad.2005.09.029
}

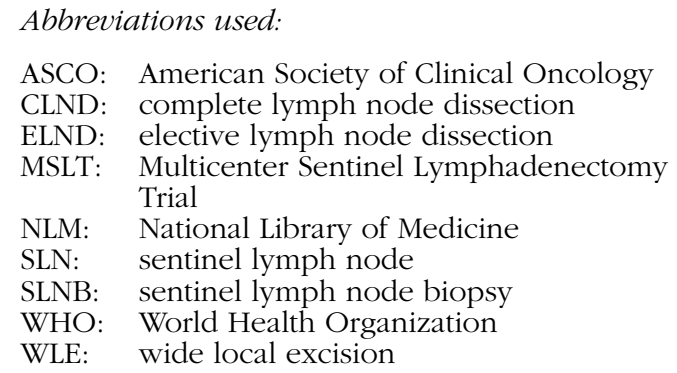

of evidence, and formulate their interpretation of data into practice.

The purpose of this review is to present the extensive available SLNB data, which are found by and large outside the core dermatology literature. It is appreciated that variable interpretation of existing evidence is certain, and final interpretations and opinions may respectfully differ from one physician to another.

\section{METHODS}

Available data, including interim results of the prospective randomized Multicenter Sentinel Lymphadenectomy Trial (MSLT)-I as publicly presented and made available on the Internet, were reviewed to determine whether the evidence supports the use of SLNB in any subset of patients with melanoma. ${ }^{7}$ The search included 1198 articles identified by a melanoma sentinel node search in the National Institutes of Health National Library of Medicine (NLM) (last date performed June, 23, 2005) with bibliographic resources including MEDLINE/PUBMED and the NLM catalog extending from 1983 to 2005 (http://www.nlm.nih.gov). Additional searches were performed in PUBMED with a total of approximately 300 additional articles reviewed (http://ncbi.nlm. nih.gov/entrez/query.fcgi).

A standard hierarchy of evidence was used to evaluate and choose studies to review based primarily on the strength of study end points combined with the strength of study design. Hierarchy of 
evidence from best to worst includes: (1) randomized clinical trials, ranked in order as (a) randomized double-blind, or (b) randomized nonblinded; (2) observational studies and published reports, ranked in order as (a) longitudinal (cohort) studies, (b) casecontrol studies/cross-sectional studies, (c) case series, or (d) case reports; and (3) prevailing expert opinion and clinical experience as documented in (a) review articles or book chapters, or (b) the authors' expertise. Systematic meta-analysis may add strength of evidence. The results of this evidentiary review are presented as a series of questions addressed by the relevant available evidence.

\section{DOES THE AVAILABLE EVIDENCE SUPPORT THE SENTINEL NODE HYPOTHESIS?}

The sentinel node hypothesis and the selective approach to complete lymph node dissection (CLND) was formally introduced in the early 1990s as a minimally invasive procedure to stage the entire nodal basin and, thus, identify those who could potentially benefit from CLND and spare those with a negative SLNB the morbidity associated with CLND. ${ }^{8,9}$ Metastasis to lymph nodes is a complex process involving many interrelated biochemical, mechanical, and molecular events. ${ }^{10}$ The SLN concept is predicated on the theory that an orderly progression of cancer cells occurs in the initial stage of the metastasis within the lymphatic system. Proponents believe that this occurs in a significant proportion of patients, although it is also recognized that direct hematogenous metastasis may occur in some without SLN metastasis. The first lymph node to which cancer cells metastasize through the lymphatics is termed the SLN. Thus, according to the hypothesis, a tumor-negative SLN can predict with high confidence the absence of metastatic disease in the rest of the primary draining nodal basin. ${ }^{2}$

Strong evidence in favor of the hypothesis that the SLN really is the first draining node is based on a strong correlation between the pathologic status of the SLN and that of the rest of the nodal basin in prospective trials and single institution and pooled data reviews, and the reproducible correlation between SLN status and overall disease-specific outcome. ${ }^{7,11-23}$ Evidence exists to support the belief that SLNB accurately identifies the SLN in patients with primary melanoma. ${ }^{2,14,24}$ The combination of preoperative lymphoscintigraphy, intraoperative gamma probe interrogation, and intraoperative injection of vital blue dye consistently provides the highest success rate in accurately identifying the SLN. The evidence does not exclude the possibility that use of preoperative lymphoscintigraphy and intraoperative gamma probe interrogation alone with omission of dye may also be as accurate as the use of all 3 localization methods. ${ }^{13,19,25-28}$

A false-negative finding, that is the presence of histologically or clinically identified metastasis in non-SLNs in patients with a negative SLN, challenges the validity of the sentinel node hypothesis. Current evidence suggests 3 main causes of false-negative findings: technical failure, pathologic failure, and biologic failure. ${ }^{16,18,29}$ A technical failure can be caused by inexperience, as available evidence strongly suggests a learning curve must take place before the SLN can be reliably identified. ${ }^{7}$ Even experienced surgeons, however, have false-negative results. Available data are conflicting regarding whether SLNB after a wide excision is associated with a higher likelihood of false-negative results, but published data and expert opinion suggest that after extensive excision, flap reconstruction, or both the false-negative rate of SLNB is increased. ${ }^{1,30,31}$ However, the existence of failures when the procedure is either performed by inexperienced surgeons or performed after excessively wide excision is not incompatible with the validity of the sentinel node hypothesis.

A pathologic failure may be caused by lack of sensitivity of current histopathology methods to identify nodal metastases that are in fact present. Available evidence strongly suggests that serial sectioning and immunohistochemistry, if hematoxylineosin staining is negative, identifies a higher percentage of positive sentinel nodes, and likely reduces pathologic false-negative cases. ${ }^{32-34}$ Evidence is less conclusive regarding how extensive the sampling of the sentinel node should be to achieve an optimum balance between cost, labor intensity, and outcome. Available evidence does not support making any clinical decisions based on molecular techniques such as reverse-transcriptase polymerase chain reaction outside of prospective clinical trials. ${ }^{13,35}$

A biologic failure may occur when lymphatics are obstructed by melanoma cells and can also occur if an inadequate initial excision is performed, leaving cells at or near the primary site that acquire the capability to disseminate secondarily through lymphatic channels into nodes other than the original SLN. The evidence indicates that these types of failure are uncommon with an experienced multidisciplinary approach consisting of nuclear medicine, surgery, and pathology, but are inevitable in some cases. ${ }^{18}$

In addition, through the knowledge gained from development and experience with the SLNB procedure, the concepts of aberrant lymphatic drainage 
pathways to unexpected nodal basins and interval nodes (also known as ectopic, intercalated, or intransit nodes) located between the primary site and the expected regional nodal basin have been elucidated. ${ }^{14,36-39}$ In our centers, at least, this has changed how physicians search for clinically detectable nodal disease, and has provided further strong support for the validity of the sentinel node hypothesis by explaining hitherto unrecognized patterns of melanoma metastasis, often falsely attributed to hematogenous dissemination in the past.

\section{DOES SLNB ACCURATELY PREDICT OUTCOME?}

The available evidence overwhelmingly supports SLN status as the most powerful independent factor predicting survival and indicates that SLNB provides the highest sensitivity and specificity of any nodal staging test available today. ${ }^{1,2,14,40-48}$ Accurate staging is widely accepted as the basis for counseling, therapeutic decision making, and prognostication in melanoma. Prognostic information is often invaluable and helps the vast majority of patients in an informed decision-making process. Some contend that metastasis to the regional lymph nodes is always associated with tumor dissemination beyond the nodes with a likely or even invariably fatal outcome. Clinical evidence does not support this notion, which is contradicted by prospective clinical trials demonstrating a significant percentage of long-term survivors with stage III disease in clinical trials and in any busy melanoma practice. ${ }^{17,49-53}$

\section{DOES SLNB RESULT IN IMPROVED REGIONAL DISEASE CONTROL?}

The evidence that SLNB followed by immediate CLND results in better regional control than delayed CLND is indirect. No study has yet been completed that would directly answer this question, and no comparative high-level data exist in terms of regional failure after nodal dissection between these groups. The prospective, randomized multinational MSLT-I trial will help answer this question. However, almost 3 decades of evidence exists regarding the regional failure rate after delayed CLND and immediate CLND (ELND or after a positive SLNB). ${ }^{11,13,16,29,50-59}$ The rates of nodal relapse reported are in the range of $0 \%$ to $10 \%$ for CLND after a positive SLNB or ELND, and $9 \%$ to 36\% after CLND for gross disease depending on the amount of gross disease (as high as 63\% with bulky disease), number of positive nodes, and the status of extracapsular spread. ${ }^{11,29,51-65}$ Regional control does not appear to be compromised by SLNB. ${ }^{50,54}$ Gershenwald et $\mathrm{al}^{54}$ reported a nodal recurrence rate of $10 \%$ in the positive SLNB/CLND basin and none were the only site of recurrence, similar to ELND trials. Expert opinion among surgical oncologists predominantly indicates that performing a delayed CLND for clinically evident disease versus an immediate CLND for microscopic disease identified by a SLNB taken as a whole differs significantly with respect to surgical complexity and resulting morbidity. ${ }^{50}$ In our own clinical practices, we have seen far fewer regional relapses and less morbidity from CLND among patients undergoing CLND after positive SLNB than among those who present with clinically evident nodal disease. Uncontrolled regional disease is recognized as a significant source of melanoma-related morbidity and can have a major negative impact on quality of life. ${ }^{11,58}$

\section{DOES SLNB IMPROVE SURVIVAL?}

The strongest case for the routine use of SLNB would be made by the demonstration of a benefit in terms of survival for all patients subjected to the procedure. No conclusive or high-level evidence exists that a positive SLNB followed by immediate CLND improves overall survival in patients with melanoma. However, some available lower-level evidence does suggest a potential subset survival benefit. $^{7,11,40,50,66-72}$

Currently, it is generally accepted that ELND is not associated with a demonstrated improvement in overall survival compared with delayed node dissection at the time of clinically evident nodal recurrence. However, approximately $80 \%$ of patients entered into the initial melanoma ELND trials do not have nodal metastasis and will survive, leaving only approximately $20 \%$ of the overall group who may benefit. Survival end point differences between randomized groups are, thus, impossible to prove without many more patients in each randomized study arm than done in any ELND trial, especially if a relatively small subset does benefit. The majority of randomized controlled ELND trials did not include preoperative lymphoscintigraphy, which may also impact the overall survival results between the study arms. A potential outcome benefit for early therapeutic lymph node dissection was suggested in a randomized trial of ELND versus observation conducted by the World Health Organization (WHO). ${ }^{70}$ In this trial, 240 patients with melanoma greater than $1.5 \mathrm{~mm}$ were randomized to ELND versus observation. No overall survival benefit was noted, but the group with positive nodes in the ELND (immediate CLND) arm had a 48\% 5-year survival compared with the group with positive nodes in the observation arm (delayed CLND), who had a 27\% 5-year survival ( $P=$ $.04)$. This type of post hoc analysis of prospective 
study data must be interpreted with caution, and can at best only be considered suggestive.

A single institution study compared survival between matched (but not randomized) groups of patients undergoing immediate CLND after a positive SLNB versus delayed CLND after clinical nodal disease recurrence. ${ }^{17} \mathrm{~A}$ significant improved survival in the positive SLNB with immediate CLND group versus delayed CLND of nodal metastases group was demonstrated with 5-, 10-, and 15-year survival of $73 \%, 69 \%$, and $69 \%$ versus $51 \%, 37 \%$, and $32 \%$, respectively $(P \leq .001)$. Even in the observation group that developed palpable nodal disease, therapeutic CLND was associated with long-term disease-free survival in a significant proportion, with $32 \%$ of these patients alive at 15 years and many of these likely cured of their disease.

Based on the large body of prospectively collected data, survival for patients with regional nodal disease is recognized to be based on the number of metastatic nodes, tumor burden within the node (macroscopic vs microscopic), and ulceration status of the primary melanoma. ${ }^{40,41}$ Survival for 1429 patients with lymph node metastases, subgrouped by presenting clinical stage, calculated from onset of the primary melanoma diagnosis to minimize leadtime bias, demonstrated a significant overall survival benefit for microscopic (clinically node negative, pathologically positive, $n=825$ ) versus macroscopic (clinically node positive, pathologically positive, $\mathrm{n}=604)$ detection $(P<.0001)$.

Based on the available evidence, potential subset survival benefit for subclinical detection of nodal disease followed by immediate CLND exists. The MSLT-I is the only current prospective randomized trial designed to address the survival benefit of SLNB. ${ }^{7,24}$

\section{MSLT-I: Interim results}

The first public presentation of interim results of the MSLT-I took place at the International Sentinel Node Society Conference in Los Angeles, Calif, on December 6, 2004. Subsequently, updated data with somewhat longer follow-up were presented at the American Society of Clinical Oncology (ASCO) Meeting in Orlando, Fla, on May 14, 2005. ${ }^{7}$ The MSLT-I, with a median follow-up of 59.5 months, involves 2001 patients enrolled (accrual now complete) from 18 centers worldwide, publicly reported but not published in a peer-reviewed journal. Eligible patients included those with primary cutaneous melanoma Breslow thickness of $1.0 \mathrm{~mm}$ or more, Clark level IV or higher, with clinically negative nodes, who were randomized in a 60:40 ratio to wide local excision (WLE) and SLNB versus
WLE alone. Patients with a positive SLNB in the WLE/SLNB arm underwent immediate CLND. Patients in the WLE-only arm underwent delayed CLND after clinical detection of nodal metastases.

At the first presentation in Los Angeles, Calif, in 2004, the 5-year melanoma-specific survival within the WLE/SLNB arm was $88 \%$ for patients with a negative SLNB versus $71 \%$ for patients with a positive SLNB. This significant difference provides strong, high-level evidence for the prognostic benefit of SLNB. This survival difference was maintained after 7 years, as presented at ASCO. The 7-year melanomaspecific survival for patients who were SLN positive with melanoma 1.2 - to $3.5-\mathrm{mm}$ thick in the WLE/SLNB arm who underwent immediate CLND was $69 \%$ versus $48 \%$ for patients in the WLE-only arm undergoing delayed CLND when nodal metastasis became clinically evident $(P=.0034$, relative risk $0.53,95 \%$ confidence interval $0.33,0.84$ ). This interim evidence strongly suggests that in a subset of patients with occult SLN metastasis, immediate CLND prolongs survival compared with delayed CLND when SLN metastasis become clinically evident.

Several other interesting results can be found in the available data. In the WLE/SLNB group, 19.8\% had a positive SLN. In the WLE-only group, 20.3\% experienced a lymph node basin recurrence. Similarly, in the WHO prospective ELND trial, which did not involve serial sectioning and immunohistochemistry for the nodes and did not use lymphoscintigraphy to direct the ELND, the percentage of patients who developed regional node metastases as the first site of recurrence in the observation arm was $30.5 \%$ as compared with $22 \%$ found to harbor microscopic metastases in the ELND arm. ${ }^{70,73}$ The findings argue strongly that most if not all lymph node metastases identifiable histopathologically have the potential to develop into clinically recognizable tumors.

Significant immunologic down-regulation has been reported to occur in SLNs with metastatic deposits from melanoma and many other cancer types. ${ }^{74}$ A relatively large body of data provides evidence of cytokine-mediated SLN immunosuppression associated with primary melanoma. ${ }^{74-84}$ Melanoma SLNs show a significant decrease in $\mathrm{T}$ cell-rich paracortical areas and a profound downregulation of interdigitating antigen-presenting dendritic cells, even in the absence of SLN metastasis. ${ }^{74,75}$ The local cytokine environment has a significant impact on maturation and function of dendritic cells, which favors immunosuppressive dendritic cells and SLN immune malfunction. ${ }^{82,83}$ Taken together, these results support the hypothesis that the primary melanoma interacts with the SLN as an 
immunologic unit to create a local immunosuppression that favors melanoma metastasis and growth. Additional evidence in support of this hypothesis has been reported. ${ }^{76}$ Primed Melan-A/MART-1-specific CD8 $\mathrm{T}$ cells that reside and accumulate at high frequency in metastatic lymph nodes have been shown to be functionally tolerant to tumor progression in the local microenvironment whereas those that circulate in the blood maintain strong cytotoxic functions. ${ }^{76}$ Manipulation of the local cytokine microenvironment may be able to reverse the local immune dysfunction. ${ }^{75,84}$

With respect to tumor burden, the average number of total involved nodes after CLND in the SLNB arm was 1.6 compared with 3.4 after delayed CLND in the observation arm. Only $5 \%$ with a positive SLNB had 4 or more positive nodes after immediate CLND compared with $27 \%$ after delayed CLND in the observation arm. This suggests a clinical benefit if tumor burden correlates with survival, regional control, or both.

The final point of interest in the MSLT-I analysis found that $7.4 \%$ of patients with a negative SLNB failed in the regional lymph node basin. Previous studies have demonstrated that the false-negative rate for SLNB is relatively low but present. ${ }^{13,24,85}$ The false-negative rate in 2784 patients with a median follow-up of 18 months in the sunbelt randomized trial was $1.5 \%$ on the head and neck, and $0.5 \%$ on the trunk and extremities. ${ }^{13}$ The false-negative rate in MSLT-I was highest for melanomas located on the head and neck, and was lowest during later study time points presumably because of increasing procedural experience. The false-negative rate for surgeons performing 25 or fewer cases was 10.3\%, versus $5.2 \%$ for surgeons performing greater than 25 cases $(P=.01)$.

\section{IS THE MORBIDITY OF SLNB JUSTIFIED IN THE ABSENCE OF A PROVEN SURVIVAL BENEFIT?}

Reported rates of wound complications after CLND for advanced regional disease are high, even in centers of excellence. The overall reported rates of wound morbidity, infection, lymphedema, and delayed healing in the axilla are between $35 \%$ and $51 \%$, and $25 \%$ to $90 \%$ in the inguinal region, thought to increase with tumor burden. ${ }^{13,58}$ Realizing that definitive comparisons are impossible between studies, postoperative complications after SLNB are observed in about 5\% in comparison with 36\% after ELND. ${ }^{11,13,59}$

SLNB is not without morbidity. Results of the largest reported prospective randomized trial involving 79 centers with more than 3600 patients undergoing SLNB found an overall 4.6\% complication rate, most of which were minor versus a $23.2 \%$ complication rate after CLND in the setting of a positive SLNB. ${ }^{13}$ Complications after SLNB included hematoma/seroma $(2.31 \%)$, minor wound infection (1.08\%), lymphedema (0.66\%), wound separation (0.24\%), pulmonary complication $(0.14 \%)$, sensory nerve injury $(0.14 \%)$, hemorrhage $(0.09 \%)$, thrombophlebitis $(0.09 \%)$, deep vein thrombosis $(0.09 \%)$, motor nerve injury (0.09\%), and others $(0.42 \%)$ including one allergic reaction to blue dye.

Some reports have suggested the possibility of increased risk of local or in-transit recurrence after SLNB. ${ }^{86-88}$ One large series obtained by pooling the results of two prospectively collected melanoma databases (MD Anderson, Houston, Texas, and Sydney Melanoma Unit, Australia) concluded that the overall incidence of in-transit metastases in patients undergoing SLNB is low and does not seem to have increased since the introduction of the SLNB technique. ${ }^{88}$ By multivariate analysis, intransit recurrence was predicted by Breslow depth, ulceration, and positive SLN status. The local or intransit recurrence rate in MSLT-I was $8 \%$ in the WLE/SLNB arm versus 9\% in the WLE-only arm, providing strong evidence that SLNB is not associated with an increased risk of in transit metastasis.

\section{OTHER ASPECTS OF SENTINEL NODE BIOPSY}

Although no randomized trial evidence exists, many series and reports support the use of SLNB for melanoma on the head and neck, vulva and eyelid, in pediatric patients, and during pregnancy. ${ }^{12,13,89-95}$ Radiopharmaceuticals at dosages used for SLNB carry negligible risk and are not contraindicated in pregnancy. Because of the risk of a rare but potentially catastrophic event of anaphylaxis to vital blue dye in patients who are pregnant, use of radiocolloid alone for SLNB in pregnancy is used at our institutions. ${ }^{92}$ No current evidence supports omission of a CLND after a positive SLNB. ${ }^{96-104}$ After a positive SLNB, 15\% to $21 \%$ of patients have evidence of positive non-SLN metastases after CLND. This likely represents an underestimate because these nodes are neither serial sectioned nor stained with immunohistochemistry. An analysis of the evidence regarding the use of postsurgical systemic adjuvant therapy is beyond the scope of this report. ${ }^{105}$ The available evidence overwhelmingly supports the use of SLNB to identify patients who may be candidates for adjuvant therapy and/or as an entry and stratification criterion for adjuvant therapy clinical trials. 


\section{CONCLUSION}

Future trial results, research, and discovery will certainly impact the role of SLNB in the management of melanoma and provide evidence to ultimately determine the scope and limits of the procedure. ${ }^{106-109}$ While we await the results of clinical and basic research to advance the field, the current evidence supports the use of SLNB in the management of melanoma.

\section{REFERENCES}

1. Johnson TM, Bradford CR, Gruber SB, Sondak VK, Schwartz JL. Staging workup, sentinel node biopsy, and follow-up tests for melanoma: update of current concepts. Arch Dermatol 2004;140:107-13.

2. Morton DL, Cochran AJ. The case for lymphatic mapping and sentinel lymphadenectomy in the management of primary melanoma. Br J Dermatol 2004;151:308-19.

3. Medalie N, Ackerman AB. Sentinel node biopsy has no benefit for patients whose primary cutaneous melanoma has metastasized to a lymph node and therefore should be abandoned now. Br J Dermatol 2004;151:298-307.

4. Pharis DB, Zitelli JA. The management of regional lymph nodes in cancer. Br J Dermatol 2003;149:919-25.

5. Coldiron BM. Sentinel node biopsy: who needs it? Int J Dermatol 2000;39:807-11.

6. Houghton AN, Coit DG, Chu D, Daud A, Dilawari RA, Gollob $J A$, et al. National Comprehensive Cancer Network clinical practice guidelines in oncology. V-1.205. Available at: URL:http://www.nccn.org/professionals/physician_gls/default. asp. Accessed June 24, 2005.

7. Morton DL. Interim results of the multicenter selective lymphadenectomy trial (MSLT-I) in clinical stage I melanoma. Presented at the American Society of Clinical Oncology, May 14, 2005, Orlando, Fla. Available at: URL:http://www.asco. org/ac/1,1003,_12-002511-00_18-0034-00_19-003013-00_21009,00.asp. Accessed May 24, 2005.

8. Morton DL, Wen DR, Wong JH, Economou JS, Cagle LA, Storm FK, et al. Technical details of intraoperative lymphatic mapping for early stage melanoma. Arch Surg 1992;127:392-9.

9. Fee HJ, Robinson DS, Sample WF, Graham LS, Holmes EC, Morton DL. The determination of lymph shed by colloidal gold scanning in patients with malignant melanoma: a preliminary study. Surgery 1978;84:626-32.

10. Nathanson SD. Insights into the mechanisms of lymph node metastasis. Cancer 2003;98:413-23.

11. Fife K, Thompson JF. Lymph-node metastases in patients with melanoma: what is the optimum management? Lancet Oncol 2001;2:614-21.

12. Chao C, Wong SL, Edwards MJ, Ross MI, Reintgen DS, Noyes $R D$, et al. Sentinel lymph node biopsy for head and neck melanomas. Ann Surg Oncol 2003;10:21-6.

13. McMasters KM, Noyes RD, Reintgen DS, Goydos JS, Beitsch PD, Davidson BS, et al. Lessons learned from the sunbelt melanoma trial. J Surg Oncol 2004;86:212-23.

14. Gershenwald JE, Thompson W, Mansfield PF, Lee JE, Colome $\mathrm{Ml}$, Tseng $\mathrm{CH}$, et al. Multi-institutional melanoma lymphatic mapping experience: the prognostic value of sentinel lymph node status in 612 stage I or II melanoma patients. J Clin Oncol 1999;17:976-83.

15. Gershenwald JE, Tseng $\mathrm{CH}$, Thompson W, Mansfield PF, Lee JE, Bouvet $M$, et al. Improved sentinel lymph node localization in patients with primary melanoma with the use of radiolabeled colloid. Surgery 1998;124:203-10.

16. Gershenwald JE, Colome MI, Lee JE, Mansfield PF, Tseng C, Lee JJ, et al. Patterns of recurrence following a negative sentinel lymph node biopsy in 243 patients with stage I or II melanoma. J Clin Oncol 1998;16:2253-60.

17. Morton DL, Hoon DS, Cochran AJ, Turner RR, Essner R, Takeuchi $\mathrm{H}$, et al. Lymphatic mapping and sentinel lymphadenectomy for early-stage melanoma: therapeutic utility and implications of nodal microanatomy and molecular staging for improving the accuracy of detection of nodal micrometastases. Ann Surg 2003;238:538-49.

18. Vuylsteke RJ, van Leeuwen PA, Statius Muller MG, Gietema HA, Kragt DR, Meijer S. Clinical outcome of stage I/II melanoma patients after selective sentinel lymph node dissection: long-term follow-up results. J Clin Oncol 2003;21:1057-65.

19. Krag DN, Meijer SJ, Weaver DL. Minimal-access surgery for staging of malignant melanoma. Arch Surg 1995;130:654-60.

20. Godellas CV, Berman CG, Lyman G. The identification and mapping of melanoma regional nodal metastases: minimally invasive surgery for the diagnosis of nodal metastases. Am Surg 1995;61:97-101.

21. Thompson JF. The Sydney melanoma unit experience of sentinel lymphadenectomy for melanoma. Ann Surg Oncol 2001;8(Suppl):44S-7S.

22. Pijpers R, Borgstein PJ, Meijer S, Hoekstra OS, van Hattum LH, Teule GJ. Sentinel node biopsy in melanoma patients: dynamic lymphoscintigraphy followed by intraoperative gamma probe and vital dye guidance. World J Surg 1997;21: 788-92.

23. Ross MI, Reintgen DS, Balch CM. Selective lymphadenectomy: emerging role for lymphatic mapping and sentinel node biopsy in the management of early stage melanoma. Semin Surg Oncol 1993;9:219-23.

24. Morton DL, Thompson JF, Essner R, Elashoff R, Stern SL, Nieweg $O E$, et al. Validation of the accuracy of intraoperative lymphatic mapping and sentinel lymphadenectomy for early-stage melanoma: a multicenter trial. Ann Surg 1999; 230:453-63.

25. Albertini JJ, Cruse CW, Rapaport D, Wells K, Ross MI, DeConti R. Intraoperative radio-lymph-scintigraphy improves sentinel lymph node identification for patients with melanoma. Ann Surg 1996;223:217-24.

26. Harlow SP, Krag DN, Ashikaga T, Weaver DL, Meijer SJ, Loggie BW, et al. Gamma probe guided biopsy of the sentinel node in malignant melanoma: a multicentre study. Melanoma Res 2001;11:45-55.

27. Robert ME, Wen DR, Cochran AJ. Pathological evaluation of the regional lymph nodes in malignant melanoma. Semin Diagn Pathol 1993;10:102-15.

28. Cochran AJ, Wen DR, Morton DL. Occult tumor cells in the lymph nodes of patients with pathological stage I malignant melanoma: an immunohistological study. Am J Surg Pathol 1988;12:612-8.

29. Wagner JD, Ranieri J, Evdokimow DZ, Logan T, Chuang TY, Johnson CS, et al. Patterns of initial recurrence and prognosis after sentinel lymph node biopsy and selective lymphadenectomy for melanoma. Plast Reconstr Surg 2003; 112:486-97.

30. Leong SP, Thelmo MC, Kim RP, Gokhale R, Rhee JY, Achtem TA, et al. Delayed harvesting of sentinel lymph nodes after previous wide local excision of extremity melanoma. Ann Surg Oncol 2003;10:196-200.

31. Kelemen PR, Essner R, Foshag L, Morton DL. Lymphatic mapping and sentinel lymphadenectomy after wide local 
excision of primary melanoma. J Am Coll Surg 1999;189: 247-52.

32. Karimipour DJ, Lowe L, Su L, Hamilton T, Sondak V, Johnson TM, et al. Standard immunostains for melanoma in sentinel lymph node specimens: which ones are most useful? J Am Acad Dermatol 2004;50:759-64.

33. Spanknebel K, Coit DG, Bieligk SC, Gonen M, Rosai J, Klimstra DS. Characterization of micrometastatic disease in melanoma sentinel lymph nodes by enhanced pathology: recommendations for standardizing pathologic analysis. Am J Surg Pathol 2005;29:305-17.

34. Gietema HA, Vuylsteke RJ, de Jonge IA, van Leeuwen PA, Molenkamp BG, van der Sijp JR, et al. Sentinel lymph node investigation in melanoma: detailed analysis of the yield from step sectioning and immunohistochemistry. J Clin Pathol 2004;57:618-20.

35. Kammula US, Ghossein R, Bhattacharya S, Coit DG. Serial follow-up and the prognostic significance of reverse transcriptase-polymerase chain reaction-staged sentinel lymph nodes from melanoma patients. J Clin Oncol 2004;22: 3989-96.

36. Thompson JF, Uren RF, Shaw HM, McCarthy WH, Quinn MJ, O'Brien CJ, et al. Location of sentinel lymph nodes in patients with cutaneous melanoma: new insights into lymphatic anatomy. J Am Coll Surg 1999;189:195-204.

37. Thompson JF, Uren RF. Teaching points on lymphatic mapping for melanoma from the Sydney melanoma unit. Semin Oncol 2004;31:349-56.

38. McMasters KM, Chao C, Wong SL, Wrightson WR, Ross MI, Reintgen DS, et al. Interval sentinel lymph nodes in melanoma. Arch Surg 2002;137:543-7.

39. Uren RF, Howman-Giles R, Thompson JF, McCarthy WH, Quinn MJ, Roberts JM, et al. Interval nodes: the forgotten sentinel nodes in patients with melanoma. Arch Surg 2000; 135:1168-72.

40. Balch CM, Soong SJ, Gershenwald JE, Thompson JF, Reintgen DS, Cascinelli N, et al. Prognostic factors analysis of 17,600 melanoma patients: validation of the American Joint Committee on Cancer melanoma staging system. J Clin Oncol 2001;19:3622-34.

41. Balch CM, Buzaid AC, Soong SJ, Atkins MB, Cascinelli N, Coit $D G$, et al. Final version of the American Joint Committee on Cancer staging system for cutaneous melanoma. J Clin Oncol 2001;19:3635-48.

42. Miranda EP, Gertner M, Wall J, Grace E, Kashani-Sabet M, Allen $\mathrm{R}$, et al. Routine imaging of asymptomatic melanoma patients with metastasis to sentinel lymph nodes rarely identifies systemic disease. Arch Surg 2004;139:831-6.

43. Ferrone CR, Panageas KS, Busam K, Brady MS, Coit DG. Multivariate prognostic model for patients with thick cutaneous melanoma: importance of sentinel lymph node status. Ann Surg Oncol 2002;9:637-45.

44. Gershenwald JE, Mansfield PF, Lee JE, Ross MI. Role for lymphatic mapping and sentinel lymph node biopsy in patients with thick ( $\geq 4 \mathrm{~mm}$ ) primary melanoma. Ann Surg Oncol 2000;7:160-5.

45. Thompson JF, Shaw HM. The prognosis of patients with thick primary melanomas: is regional lymph node status relevant, and does removing positive regional nodes influence outcome? Ann Surg Oncol 2002;9:719-22.

46. Tsao $H$, Feldman M, Fullerton JE, Sober AJ, Rosenthal D, Goggins W. Early detection of asymptomatic pulmonary melanoma metastases by routine chest radiographs is not associated with improved survival. Arch Dermatol 2004;140: 67-70.
47. Hafner J, Schmid MH, Kempf W, Burg G, Kunzi W, MeuliSimmen $C$, et al. Baseline staging in cutaneous malignant melanoma. Br J Dermatol 2004;150:677-86.

48. Wang TS, Johnson TM, Cascade PN, Redman BG, Sondak VK, Schwartz JL. Evaluation of staging chest radiographs and serum lactate dehydrogenase for localized melanoma. J Am Acad Dermatol 2004;51:399-405.

49. White RR, Stanley WE, Johnson JL, Tyler DS, Seigler HF. Longterm survival in 2,505 patients with melanoma with regional lymph node metastasis. Ann Surg 2002;235:879-87.

50. Pawlik TM, Ross MI, Gershenwald JE. Lymphatic mapping in the molecular era. Ann Surg Oncol 2004;11:362-74.

51. Meyer T, Merkel S, Gohl J, Hohenberger W. Lymph node dissection for clinically evident lymph node metastases of malignant melanoma. Eur J Surg Oncol 2002;28:424-30.

52. Shaw JHF, Rumball EM. Complications and local recurrence following lymphadenectomy. Br J Surg 1990;77:7604.

53. Karakousis CP, Goumas W, Rao U, Driscoll DL. Axillary node dissection in malignant melanoma. Am J Surg 1991;162:2027.

54. Gershenwald JE, Berman RS, Porter G, Mansfield PF, Lee JE, Ross MI. Regional nodal basin control is not compromised by previous sentinel lymph node biopsy in patients with melanoma. Ann Surg Oncol 2000;7:226-31.

55. Fincher TR, McCarty TM, Fisher TL, Preskitt JT, Lieberman ZH, Stephens JF, et al. Patterns of recurrence after sentinel lymph node biopsy for cutaneous melanoma. Am J Surg 2003;186: 675-81.

56. Clary BM, Brady MS, Lewis JJ, Coit DG. Sentinel lymph node biopsy in the management of patients with primary cutaneous melanoma: review of a large single-institutional experience with an emphasis on recurrence. Ann Surg 2001;233: 250-8.

57. Statius Muller MG, van Leeuwen PA, van Diest PJ, Pijpers R, Nijveldt RJ, Vuylsteke RJ, et al. Pattern and incidence of first site recurrences following sentinel node procedure in melanoma patients. World J Surg 2002;26:1405-11.

58. Serpell JW, Carne PW, Bailey M. Radical lymph node dissection for melanoma. ANZ J Surg 2003;73:294-9.

59. Blumenthal $R$, Banic $A$, Brand $C U$, Ris $H B$, Lardinois $D$. Morbidity and outcome after sentinel lymph node dissection in patients with early-stage malignant cutaneous melanoma. Swiss Surg 2002;8:209-14.

60. Lee RJ, Gibbs JF, Proulx GM, Kollmorgen DR, Jia C, Kraybill WG. Nodal basin recurrence following lymph node dissection for melanoma: implications for adjuvant radiotherapy. Int J Radiat Oncol Biol Phys 2000;46:467-74.

61. Pidhorecky I, Lee RJ, Proulx G, Kollmorgen DR, Jia C, Driscoll $\mathrm{DL}$, et al. Risk factors for nodal recurrence after lymphadenectomy for melanoma. Ann Surg Oncol 2001;8:109-15.

62. Slingluff CL Jr, Stidham KR, Ricci WM, Stanley WE, Seigler HF. Surgical management of regional lymph nodes in patients with melanoma: experience with 4682 patients. Ann Surg 1994;219:120-30.

63. Calabro A, Singletary SE, Balch CM. Patterns of relapse in 1001 consecutive patients with melanoma nodal metastases. Arch Surg 1989;124:1051-5.

64. Ballo MT, Strom EA, Zagars GK, Bedikian AY, Prieto VG, Mansfield PF, et al. Adjuvant irradiation for axillary metastases from malignant melanoma. Int J Radiat Oncol Biol Phys 2002;52:964-72.

65. Strom EA, Ross MI. Adjuvant radiation therapy after axillary lymphadenectomy for metastatic melanoma: toxicity and local control. Ann Surg Oncol 1995;2:445-9.

66. Kretschmer L, Hilgers R, Mohrle M, Balda BR, Breuninger $H$, Konz B, et al. Patients with lymphatic metastasis of cutaneous 
malignant melanoma benefit from sentinel lymphonodectomy and early excision of their nodal disease. Eur J Cancer 2004;40:212-8.

67. Kretschmer L, Beckmann I, Thoms KM, Haenssle H, Bertsch $\mathrm{HP}$, Neumann CH. Sentinel lymphonodectomy does not increase the risk of loco-regional cutaneous metastases of malignant melanomas. Eur J Cancer 2005;41:531-8.

68. Kretschmer L, Preusser KP, Marsch WC, Neumann C. Prognostic factors of overall survival in patients with delayed lymph node dissection for cutaneous malignant melanoma. Melanoma Res 2000;10:483-9.

69. Balch CM, Soong S, Ross MI, Urist MM, Karakousis CP, Temple WJ, et al. Long-term results of a multi-institutional randomized trial comparing prognostic factors and surgical results for intermediate thickness melanomas (1.0 to $4.0 \mathrm{~mm}$ ): intergroup melanoma surgical trial. Ann Surg Oncol 2000;7: 87-97.

70. Cascinelli N, Morabito A, Santinami M, MacKie RM, Belli F. Immediate or delayed dissection of regional nodes in patients with melanoma of the trunk: a randomized trial; WHO melanoma programme. Lancet 1998;351:793-6.

71. Balch CM, Soong SJ, Bartolucci AA, Urist MM, Karakousis CP, Smith TJ, et al. Efficacy of an elective regional lymph node dissection of 1 to $4 \mathrm{~mm}$ thick melanomas for patients 60 years of age and younger. Ann Surg 1996;224:255-63.

72. Balch CM, Buzaid AC, Atkins MB, Cascinelli N, Coit DG, Fleming ID. A new American Joint Committee on Cancer staging system for cutaneous melanoma. Cancer 2000;88: 1484-91.

73. Veronesi U, Adamus J, Bandiera DC, Brennhovd IO, Caceres E, Cascinelli $\mathrm{N}$, et al. Inefficacy of immediate node dissection in stage 1 melanoma of the limbs. N Engl J Med 1977;297: 627-30.

74. Cochran AJ, Morton DL, Stern S, Lana AM, Essner R, Wen DR. Sentinel lymph nodes show profound downregulation of antigen-presenting cells of the paracortex: implications for tumor biology and treatment. Mod Pathol 2001;14:604-8.

75. Lee JH, Torisu-Itakara H, Cochran AJ, Kadison A, Huynh $\mathrm{Y}$, Morton DL, et al. Quantitative analysis of melanoma-induced cytokine-mediated immunosuppression in melanoma sentinel nodes. Clin Cancer Res 2005;11:107-12.

76. Zippelius A, Batard P, Rubio-Godoy V, Bioley G, Lienard D, Lejeune $F$, et al. Effector function of human tumor-specific CD8 T cells in melanoma lesions: a state of local functional tolerance. Cancer Res 2004;64:2865-73.

77. Botella-Estrada R, Dasi F, Ramos D, Nagore E, Herrero MJ, Gimenez J, et al. Cytokine expression and dendritic cell density in melanoma sentinel nodes. Melanoma Res 2005;15: 99-106.

78. Hoon DS, Bowker RJ, Cochran AJ. Suppressor cell activity in melanoma-draining lymph nodes. Cancer Res 1987;47: 1529-33.

79. Cochran AJ, Pihl E, Wen DR, Hoon DS, Korn EL. Zoned immune suppression of lymph nodes draining malignant melanoma: histologic and immunohistologic studies. J Natl Cancer Inst 1987;78:399-405.

80. Hoon DS, Korn EL, Cochran AJ. Variations in functional immunocompetence of individual tumor-draining lymph nodes in humans. Cancer Res 1987;47:1740-4.

81. Lana AM, Wen DR, Cochran AJ. The morphology, immunophenotype and distribution of paracortical dendritic leucocytes in lymph nodes regional to cutaneous melanoma. Melanoma Res 2001;11:401-10.

82. Frumento G, Rotondo R, Tonetti M, Damonte G, Benatti U, Ferrara GB. Tryptophan-derived catabolites are responsible for inhibition of T and natural killer cell proliferation induced by indoleamine 2,3-dioxygenase. J Exp Med 2002;196:459-68. 83. Munn DH, Zhou M, Attwood JT, Bondarev I, Conway SJ, Marshall B, et al. Prevention of allogeneic fetal rejection by tryptophan catabolism. Science 1998;281:1191-3.

84. Vuylsteke RJ, Molenkamp BG, Gietema HA, van Leeuwen PA, Wijnands PG, Vos W, et al. Local administration of granulocyte/macrophage colony-stimulating factor increases the number and activation state of dendritic cells in the sentinel lymph node of early-stage melanoma. Cancer Res 2004;64: 8456-60.

85. Ross MI. The case for elective lymphadenectomy. Surg Oncol Clin North Am 1992;1:205.

86. Estourgie SH, Nieweg OE, Kroon BB. High incidence of intransit metastases after sentinel node biopsy in patients with melanoma. Br J Surg 2004;91:1370-1.

87. Thomas JM, Clark MA. Selective lymphadenectomy in sentinel node-positive patients may increase the risk of local/intransit recurrence in malignant melanoma. Eur J Surg Oncol 2004;30:686-91.

88. Pawlik TM, Ross MI, Johnson MM, Schacherer CW, McClain DM, Mansfield PF, et al. Predictors and natural history of intransit melanoma after sentinel lymphadenectomy. Ann Surg Oncol 2005; 12:587-96.

89. Pacella SJ, Lowe L, Bradford C, Marcus BC, Johnson T, Rees R. The utility of sentinel lymph node biopsy in head and neck melanoma in the pediatric population. Plast Reconstr Surg 2003;112:1257-65.

90. Schmalbach CE, Nussenbaum B, Rees RS, Schwartz J, Johnson TM, Bradford CR. Reliability of sentinel lymph node mapping with biopsy for head and neck cutaneous melanoma. Arch Otolaryngol Head Neck Surg 2003;129:61-5.

91. Wechter ME, Gruber SB, Haefner HK, Lowe L, Schwartz JL, Reynolds KR, et al. Vulvar melanoma: a report of 20 cases and review of the literature. J Am Acad Dermatol 2004;50:554-62.

92. Schwartz JL, Mozurkewich EL, Johnson TM. Current management of patients with melanoma who are pregnant, want to get pregnant, or do not want to get pregnant. Cancer 2003;97: 2130-3.

93. Nijhawan N, Ross Ml, Diba R, Ahmadi MA, Esmaeli B. Experience with sentinel lymph node biopsy for eyelid and conjunctival malignancies at a cancer center. Ophthal Plast Reconstr Surg 2005;21:10.

94. Neville HL, Andrassy RJ, Lally KP, Corpron C, Ross MI. Lymphatic mapping with sentinel node biopsy in pediatric patients. J Pediatr Surg 2000;35:961-4.

95. Esmaeli B. Sentinel node biopsy as a tool for accurate staging of eyelid and conjunctival malignancies. Curr Opin Ophthalmol 2002;13:317-23.

96. Lee JH, Essner R, Torisu-Itakura $H$, Wanek L, Wang $H$, Morton $\mathrm{DL}$. Factors predictive of tumor-positive nonsentinel lymph nodes after tumor-positive sentinel lymph node dissection for melanoma. J Clin Oncol 2004;22:3677-84.

97. Vuylsteke RJ, Borgstein PJ, van Leeuwen PA, Gietema HA, Molenkamp BG, Muller MG, et al. Sentinel lymph node tumor load: an independent predictor of additional lymph node involvement and survival in melanoma. Ann Surg Oncol 2005; 12:440-8.

98. Salti Gl, Das Gupta TK. Predicting residual lymph node basin disease in melanoma patients with sentinel lymph node metastases. Am J Surg 2003;186:98-101.

99. Sabel MS, Griffith K, Sondak VK, Lowe L, Schwartz JL, Cimmino VM, et al. Predictors of nonsentinel lymph node positivity in patients with a positive sentinel node for melanoma. J Am Coll Surg 2005;201:37-47. 
100. Reeves ME, Delgado R, Busam KJ, Brady MS, Coit DG. Prediction of nonsentinel lymph node status in melanoma. Ann Surg Oncol 2003;10:27-31.

101. McMasters KM, Wong SL, Edwards MJ, Chao C, Ross Ml, Noyes RD, et al. Frequency of nonsentinel lymph node metastasis in melanoma. Ann Surg Oncol 2002;9:137-41.

102. Elias N, Tanabe KK, Sober AJ, Gadd MA, Mihm MC, Goodspeed $B$, et al. Is completion lymphadenectomy after a positive sentinel lymph node biopsy for cutaneous melanoma always necessary? Arch Surg 2004;139:400-4.

103. Cochran AJ, Wen DR, Huang RR, Wang HJ, Elashoff R, Morton DL. Prediction of metastatic melanoma in nonsentinel nodes and clinical outcome based on the primary melanoma and the sentinel node. Mod Pathol 2004;17:747-55.

104. Dewar DJ, Newell B, Green MA, Topping AP, Powell BW, Cook MG. The microanatomic location of metastatic melanoma in sentinel lymph nodes predicts nonsentinel lymph node involvement. J Clin Oncol 2004;22:3345-9.

105. Sabel MS, Sondak VK. Pros and cons of adjuvant interferon in the treatment of melanoma. Oncologist 2003;8:451-8.

106. Haqq C, Nosrati M, Sudilovsky D, Crothers J, Khodabakhsh D, Pulliam BL, et al. The gene expression signatures of melanoma progression. Proc Natl Acad Sci U S A 2005;102:6092-7.

107. Bittner $M$, Meltzer $P$, Chen $Y$, Jiang $Y$, Seftor $E$, Hendrix $M$, et al. Molecular classification of cutaneous malignant melanoma by gene expression profiling. Nature 2000;406: 536-40.

108. Pardal R, Clarke MF, Morrison SJ. Applying the principles of stem-cell biology to cancer. Nat Rev Cancer 2003;3:895-902.

109. Carlson JA, Ross JS, Slominski A, Linette G, Mysliborski J, Hill J, et al. Molecular diagnostics in melanoma. J Am Acad Dermatol 2005;52:743-75.

\section{ECZEMA HERPETICUM PATIENTS NEEDED FOR REFERRAL}

The Atopic Dermatitis and Vaccinia Network $(A D V N)$, a consortium of 5 medical centers, is charged with developing and implementing a plan to reduce the risk of eczema vaccinatum (a potentially lifethreatening complication of smallpox vaccine immunization). ADVN is conducting a study to elucidate the mechanism predisposing patients with atopic dermatitis (AD) to eczema vaccinatum. As smallpox vaccinations are currently not conducted, we will compare the genetic make-up of subjects with eczema herpeticum $(\mathrm{EH})$ compared to $\mathrm{AD}$ subjects without $\mathrm{EH}$.

\section{The consortium is seeking:}

Persons 1-80 years old with AD and a positive lab test for herpes simplex (PCR, immunofluoresence, culture, or Tzanck prep) and who self-report as either African American or Caucasian.

If you know patients with a history of eczema herpeticum, please ask them to contact one of the participating centers or direct them to our Web site (www.atopicderm.org)

\section{Participating Centers:}

- National Jewish Medical and Research Center, Denver, CO

PI: Donald Leung, MD, PhD, 303-398-1067

- Oregon Health and Science University, Portland, OR

PI: Jon Hanifin, 503-494-2121

- University of California at San Diego, San Diego, CA

PIs: Rich Gallo, MD, PhD and Tissa Hata, MD, 858-657-8390

- Children's Hospital, Boston, MA

PI: Lynda Schneider, MD, 617-355-6127

- Johns Hopkins Asthma and Allergy Center, Baltimore, MD

PIs: Lisa Beck, MD, and Kathleen Barnes, PhD, 410-550-4763 